\title{
III Foro de Enseñanza de las Ciencias
}

Marta Massa

Elisa Petrone

(Universidad Nacional de Rosario. Argentina)

Este evento, realizado en Rosario el día 4 de Noviembre de 2009, ha sido organizado por las Secretarías de Extensión, Ciencia y Técnica y Académica del Rectorado de la Universidad Nacional de Rosario, el Instituto de Educación Superior $N^{\circ} 28$ Olga Cossettini y el Instituto Rosario de Investigación en Ciencias de la Educación. El mismo dio continuidad a un espacio iniciado en Noviembre de 2008 destinado al desarrollo de actividades conjuntas de reflexión y propuesta de acciones educativas relativas a la enseñanza de las Ciencias, integrado por especialistas y docentes de los niveles secundario, terciario y universitario.

En esta oportunidad se presentaron inicialmente resultados de un estudio, llevado a cabo a principios de este año, relativo a conocimientos generales sobre ciencias naturales que tienen estudiantes al comienzo de carreras universitarias y terciarias, generándose un interesante espacio de debate relativo a la interpretación de los mismos.

A continuación tres especialistas participaron de un panel exponiendo aspectos relativos a la enseñanza y aprendizaje de Matemática, Ciencias Naturales y Ciencias Sociales, aportando elementos iniciales de análisis que actuaron como disparadores e insumo para la posterior discusión grupal en cada uno de los tres Talleres organizados a tal fin.

En el transcurso de los Talleres, en los que participaron docentes de los niveles secundario, terciario y universitario y estudiantes de profesorados, se abordaron cuestiones generadas a partir de los siguientes ejes de discusión:

a) Los contenidos de Matemática correspondientes a nuestra actual escuela secundaria están organizados en cinco ejes, atendiendo a aspectos principalmente epistémicos.

¿Cuáles herramientas metodológicas resultan más apropiadas para el diseño de situaciones didácticas en cada uno de los ejes?

b) Frente a la diversidad de contenidos de Ciencias Experimentales establecidos curricularmente para la educación secundaria: 
¿Cómo orientar el diseño de situaciones didácticas innovadoras?

¿Cómo trabajar en contextos locales los contenidos curriculares?

c) ¿Cómo enseñamos Ciencias Sociales en la escuela?

Luego de una activa participación en los talleres, se expusieron las conclusiones del trabajo en el plenario de cierre. Una síntesis de las mismas se expone a continuación.

\section{Taller de Matemática}

Se procedió al análisis de las prácticas áulicas, procurando determinar recursos que resultarían eficientes para mejorar los procesos de enseñanza y de aprendizaje de Matemática:

- En la escuela secundaria se recurre poco al uso de materiales concretos (objetos de uso cotidiano con formas geométricas, diversos tipos de software y diferentes portadores de información numérica de uso social -tarifas, facturas-) como facilitadores del aprendizaje, en parte porque implica la preparación extra de esos elementos y también porque se subestima la riqueza intelectual de este tipo de actividad: con base en lo conocido de la realidad y/o saberes previos, con un razonamiento intuitivo, se comienza a explorar un campo de conocimientos, orientando el hacer de los alumnos hacia la conceptualización y formalización procurada.

- El empleo de un libro de texto adecuado, con un buen desarrollo teórico que aúne la resolución de problemas con el marco conceptual, es otra herramienta metodológica bastante olvidada. Manejar eficazmente un texto es parte de una alfabetización general.

- La importancia de concluir la resolución de problemas con una formulación completa y clara de la respuesta a la pregunta enunciada, como actividad de síntesis y validación.

- El afianzamiento de los contenidos requiere de una profusa actividad que, a través del trabajo autónomo y capitalización de la experiencia proporcionada por el análisis de errores cometidos, fortalezca la significatividad del aprendizaje.

- El poco tiempo asignado en la escuela secundaria y atendiendo a los dos fines de la misma: formar para el mundo del trabajo y la función propedéutica, obligan al docente a procurar un delicado equilibrio entre el aprender a pensar estratégica e integralmente, mediante el abordaje de variadas situaciones problemáticas, y el manejo eficaz y seguro de variadas herramientas procedimentales necesarias para encarar estudios superiores.

\section{Taller de Ciencias Naturales}

El grupo centró el análisis sobre el lenguaje, en cuanto portador de comunicación y mediador de conocimiento. Se consideró que: 
La construcción del lenguaje científico requiere una clara diferenciación de conceptos, con un único significado. Es necesario trabajar sistemáticamente para construir la monosemia propia del lenguaje científico.

La falta de comprensión de consignas en los protocolos de laboratorio constituye una dificultad que inhibe a los estudiantes en la acción. Esto se revierte cuando el docente inicia el diálogo con ellos y mediante las preguntas logra que los estudiantes comprendan las actividades a realizar y se involucren en ellas con interés y creatividad.

La necesidad de establecer una comunicación bidireccional a través del diálogo en el aula, en la cual se logre que el estudiante abandone su pasividad.

La importancia de trabajar la comprensión lectora, abordando la misma desde la propia disciplina y no como responsabilidad del área de Lengua.

La importancia de poner la "química" en contexto diferenciándola de la que se enseña para carreras del área de salud para las vinculadas a las ingenierías, donde los campos de aplicación son claramente diferentes. En particular, se discutió la importancia de acostumbrar a los estudiantes al uso de los nombres específicos de los elementos químicos o a la diferenciación entre sustancias que se distinguen por su composición.

La necesidad de establecer relaciones entre las distintas disciplinas para integrar los conocimientos y ubicándolos en el contexto histórico-social de su producción.

\section{Taller de Ciencias Sociales}

A partir de experiencias comentadas, se estableció:

La necesidad de integración de todas las ciencias, mediante propuestas centradas en problemáticas que permitan esta interrelación.

La recuperación de los saberes de los alumnos, para hacerlos sentir partícipes de la historia, vinculando lo emotivo con lo cognitivo.

La diferenciación entre conocimiento y saber.

La importancia de "enseñar a pensar" pero no sólo para comprender el mundo sino poder modificarlo. Para ello es imprescindible desarrollar las habilidades cognitivas.

La recuperación del compromiso social y la intervención socio comunitaria que proponen las Ciencias Sociales: "percibir la humanidad".

La necesidad de contextualizar los saberes para interesar y movilizar al alumno.

La dificultad para pensar las herramientas metodológicas, que no pueden examinarse por fuera de otras discusiones políticas "macro", que atraviesan al ciudadano actual.

Se propuso retomar la metodología del historiador para construir fuentes históricas desde el relato oral, desde la memoria viva. 
Los aspectos mencionados contribuyeron a orientar problemáticas de interés para su tratamiento en el próximo Foro a realizarse en Abril de 2010. 